\title{
GRID-TIE THREE-PHASE INVERTER WITH ACTIVE AND REACTIVE POWER FLOW CONTROL CAPABILITY
}

\author{
Leonardo P. Sampaio', Moacyr A. G. de Brito ${ }^{2}$, Guilherme de A. e Melo ${ }^{3}$, Carlos A. Canesin ${ }^{3}$ \\ ${ }^{1}$ Universidade Tecnológica Federal do Paraná - UTFPR-CP \\ Cornélio Procópio-PR, Brasil. \\ ${ }^{2}$ Universidade Tecnológica Federal do Paraná - UTFPR-CM \\ Campo Mourão-PR, Brasil. \\ ${ }^{3}$ Universidade Estadual Paulista - UNESP-FE/IS \\ Ilha Solteira-SP, Brasil. \\ e-mails: ${ }^{1}$ sampaio@utfpr.edu.br; ${ }^{3}$ canesin@dee.feis.unesp.br
}

\begin{abstract}
This paper proposes a methodology for the active and reactive power flow control, applied to a low voltage grid-tie three-phase power inverter. The control technique is designed by means of feedback linearization and the pole placement is obtained using Linear Matrix Inequalities (LMIs) together with D-stability concepts. Through multi-loop control, the power loop uses adapted active and reactive power transfer expressions, in order to obtain the magnitude of the voltage and the power transfer angle to control the power flow between the distributed generation (DG) and the utility grid. The state-feedback linearization technique is applied at the whole control system in order to minimize the nonlinearities of the system, improving the controller's performance and mitigating potential disturbances. The methodology main idea is to obtain the best controllers with the lowest gains as possible placing the poles in the left-half s-plane region specified during the design procedure, resulting in fast responses with reduced oscillations. Demonstrating the feasibility of the proposal a 3 kVA three-phase prototype was experimentally implemented. Furthermore, experimental results demonstrate anti-islanding detection and protection against over/under voltage and frequency deviations.
\end{abstract}

Keywords - Distributed Generation, Feedback Linearization, Linear Matrix Inequalities, Microgrid, Power Flow Control, Robust Control.

\section{INTRODUCTION}

The traditional electricity generation scenario has been changing considering that most part of its conventional generation results in pollutant processes, and consequently it causes risks and impacts to the environment and human being. The new generation scenario is been modified as it uses alternative and renewable electrical energy sources with the concept of Distributed Generation (DG), next to the consumption centers, integrating its electricity sources such as photovoltaic, wind, fuel cell, and others with the conventional distribution electricity utility in alternating current (AC) [1]-[4]. In 2030, the global electrical energy consumption is estimated to be increased more than $50 \%$ compared to 2008 [5].

Manuscript received 03/02/2014; revised 01/06/2014; accepted for publication 11/11/2014, by recommendation of the Special Section Editor Mário Lúcio da Silva Martins.
In order to supply the grid with electricity produced by the alternative energy sources, different kinds of power converter structures have been proposed in the last years, such as single and three-phase arrangement [6]-[10]. The most used structure is the voltage source inverter (VSI), which is controlled as current source. In order to deal with the threephase structures the control techniques can be applied in the abc-axes, alpha-beta-axes and dq-axes. The advantage of the last approach is that all the systems variables are dc values for the fundamental frequency [10],[11], which quite simplifies the control laws.

Therefore, several control techniques in power electronics are based on reference tracking, e.g., dq theory. The linear model used to set the controller is obtained by means of a small signal analysis, which is linearized for the operational quiescent point [12]. The most well-known and used compensator to operate with this linear model, is the Proportional-Integral-Derivative Controller (PID) [12], [13]. Sometimes, the converter can operate out of the specified boundary, which can produce undesirable results and at worst case, the system can operate out of the stable region.

Providing better control results, new power electronics control schemes can handle with systems nonlinearities by applying nonlinear control techniques [14]. One of its possible uses is to find a better linear approximation around one operation quiescent point, attenuating those systems nonlinearities, dealing with models uncertainties and working at wide-operating-range [14]-[17].

Recently researches have been proposing the linear matrix inequalities (LMI) as a better solution to control several applications. In order to guarantee the robustness of the system, the LMI techniques can be applied to reject or minimize system perturbations, finding the best controllers in a multi-objective problem working with polytopic uncertainties [18]-[22].

The LMI tools together with the D-Stability criteria are powerful tools to be applied in pole placement designs for feedback systems. Its techniques can work with several conditions, e.g., to determine the best controller with minimum oscillations and high-speed transient response. The presented D-stability proposes the usage of the decay rates to restrain a maximum time to the vector norm [23]-[26].

The proposed control technique aims to control the active and reactive power flow between the DG and utility grid, based on the power transfer equations applying proportionalintegral (PI) controllers designed by linear matrix inequalities (LMI) together with D-stability concepts. The 
section II presents the converter structure and the proposed control; the simulation results is demonstrated in section III and in section IV are presented the conclusions and final considerations.

\section{THE PROPOSED CONTROL}

The proposed control technique has the purpose to control the active power injection and reactive power compensation for alternating current low voltage (AC-LV) grids. The power flow control uses the well-known active (1) and reactive (2) power transfer expressions to determine the power transfer angle and the peak of the reference voltage to be tracked by the VSI capacitor. For minimizing the order of the control system the VSI voltage loop gives the current reference for the first filter inductor, and finally, with this current loop the three-phase modulation is obtained. So, the whole control system is performed by a multi-loop control based on power, voltage and current control loops, where all the compensators are determined using feedback linearization with LMI and D-stability criteria.

$$
\begin{aligned}
& P=\frac{V_{C f_{R M S}} V_{g_{R M S}}}{X_{L_{2}}} \sin (\delta) \\
& Q=\frac{V_{C f_{R M S}} V_{g_{R M S}}}{X_{L_{2}}} \cos (\delta)-\frac{V_{g_{R M S}}{ }^{2}}{X_{L_{2}}}
\end{aligned}
$$

Figure 1 shows the proposed grid-connected three-phase inverter control. The main $a b c$ state-space equations were transformed into $d q$ coordinates. The main state-space equations that represent the three-phase control in $d q$ coordinates can be obtained as follows:

$$
\begin{gathered}
L_{1} \frac{d}{d t}\left[\begin{array}{l}
i_{L_{1} d} \\
i_{L_{1} q}
\end{array}\right]=\left[\begin{array}{l}
d_{d} V_{D C} \\
d_{q} V_{D C}
\end{array}\right]-\left[\begin{array}{c}
V_{C d} \\
V_{C q}
\end{array}\right]-\frac{3}{2} \omega L_{2}\left[\begin{array}{c}
-i_{L_{2} q} \\
i_{L_{2} d}
\end{array}\right], \\
C \frac{d}{d t}\left[\begin{array}{l}
V_{C d} \\
V_{C q}
\end{array}\right]=\left[\begin{array}{l}
i_{L_{1} d} \\
i_{L_{1} q}
\end{array}\right]-\left[\begin{array}{l}
i_{L_{2} d} \\
i_{L_{2} q}
\end{array}\right]-\frac{3}{2} \omega C\left[\begin{array}{c}
-V_{C q} \\
V_{C d}
\end{array}\right], \\
L_{2} \frac{d}{d t}\left[\begin{array}{l}
i_{L_{2} d} \\
i_{L_{2} q}
\end{array}\right]=\left[\begin{array}{l}
V_{C d} \\
V_{C q}
\end{array}\right]-\left[\begin{array}{l}
V_{g d} \\
V_{g q}
\end{array}\right]-\frac{3}{2} \omega L_{2}\left[\begin{array}{c}
-i_{L_{2} q} \\
i_{L_{2} d}
\end{array}\right],
\end{gathered}
$$

where $d_{d}$ and $d_{q}$ represent the equivalent duty-cycle of the three-phase inverter in direct and quadrature axes, respectively.

\section{A. Feedback Linearization}

A nonlinear system [14] can be represented using the smooth and nonlinear function, as:

$$
\left\{\begin{array}{l}
\dot{x}=f(x)+g(x) u \\
y=h(x)
\end{array}\right.
$$

The input state $u$ is not directly observed in the output state $y$. The control technique applied in this work uses the feedback linearization [27]. The main idea is to transform the nonlinear system into a fully or a partially linear system. The output state must be differentiated until the input state $u$ appear in the $y^{r}$, derivative of $y$, thus, the derivate of output $y$ (6) can be described as:

$$
y^{r}=L_{f}^{r} h(x)+L_{g} L_{f}^{r-1} h(x) u
$$

where $L_{f}$ and $L_{g}$ are de derivative of the $\mathrm{f}(\mathrm{x})$ and $\mathrm{g}(\mathrm{x})$, respectively.

If $L_{g} L_{f}^{r-1} h(x) \neq 0$ for some value when $x=x_{0}$ of $\Omega_{x}$, also it is verified in the finite neighborhood of $\Omega$ in ${ }_{\mathrm{x} 0}$, the input state vector can be rewritten as:

$$
u=\frac{\left[-L_{f}^{r} h(x)+z\right]}{L_{g} L_{f}^{r-1} h(x)} .
$$

Where $\mathrm{z}$ represents the linearized term of the derivative output $y$ and can be described as:

$$
y^{r}=z \text {. }
$$

From the linearized term, the system may be arranged in order to allow that the robust control techniques are applied. Thus, the sections II.B, II.C and II.D demonstrate the linearization process applied in the current loop control, voltage loop control and power loop control, respectively. The robust control technique and the controller design are described in sections II.E and II.F, respectively.

\section{B. Current Loop Control}

The current loop provides the signal for the three-phase PWM modulation and it is required to be the fastest loop in the system. The error between the current through the inductor $L_{l d q}$ and the current reference $i_{L_{1} d q}^{*}$ can be described as:

$$
\left[\begin{array}{c}
e_{i d} \\
e_{i q}
\end{array}\right]=\left[\begin{array}{l}
i_{L_{1} d}^{*} \\
i_{L_{1} q}^{*}
\end{array}\right]-\left[\begin{array}{l}
i_{L_{1} d} \\
i_{L_{1} q}
\end{array}\right] .
$$

As the current loop has the objective to determine the VSI modulation, which it is not clearly shown in (10), the feedback linearization is applied until the modulation be clearly determined. In sequence, expression (3) was replaced into the linearization process in order to obtain the VSI modulation, as:

$$
\left[\begin{array}{l}
d_{d} \\
d_{q}
\end{array}\right]=\frac{1}{V_{D C}}\left[\begin{array}{c}
z_{i d} \\
z_{i q}
\end{array}\right]+\frac{1}{V_{D C}}\left[\begin{array}{c}
V_{C d} \\
V_{C q}
\end{array}\right]+\frac{3}{2} \frac{\omega L_{1}}{V_{D C}}\left[\begin{array}{c}
-i_{L_{1} q} \\
i_{L_{1} d}
\end{array}\right] .
$$

where:

$$
\left[\begin{array}{c}
z_{i d} \\
z_{i q}
\end{array}\right]=-L_{1}\left[\begin{array}{c}
\dot{e}_{i d} \\
\dot{e}_{i q}
\end{array}\right] .
$$

As can be noted in (10) and (12) the linearization process was applied in the derivative of the current error.

\section{Voltage Loop Control}

The voltage loop provides the current reference for the current control loop. This loop bandwidth must be greater than the grid frequency and lower than the current loop bandwidth, otherwise the output voltage can be distorted or the voltage loop may interfere in the current loop dynamics. This loop aimed to track the voltage references $V_{C d}^{*}$ and $V_{C q}^{*}$, across $\mathrm{C}$ capacitors. The error of this loop can be obtained as:

$$
\left[\begin{array}{c}
e_{V d} \\
e_{V q}
\end{array}\right]=\left[\begin{array}{c}
V_{C d}^{*} \\
V_{C q}^{*}
\end{array}\right]-\left[\begin{array}{c}
V_{C d} \\
V_{C q}
\end{array}\right] \text {. }
$$

Applying the derivative of the voltage error (13) with respect to the time, replacing (4) and linearizing this derivative of voltage error, the current reference can be expressed as (14). 


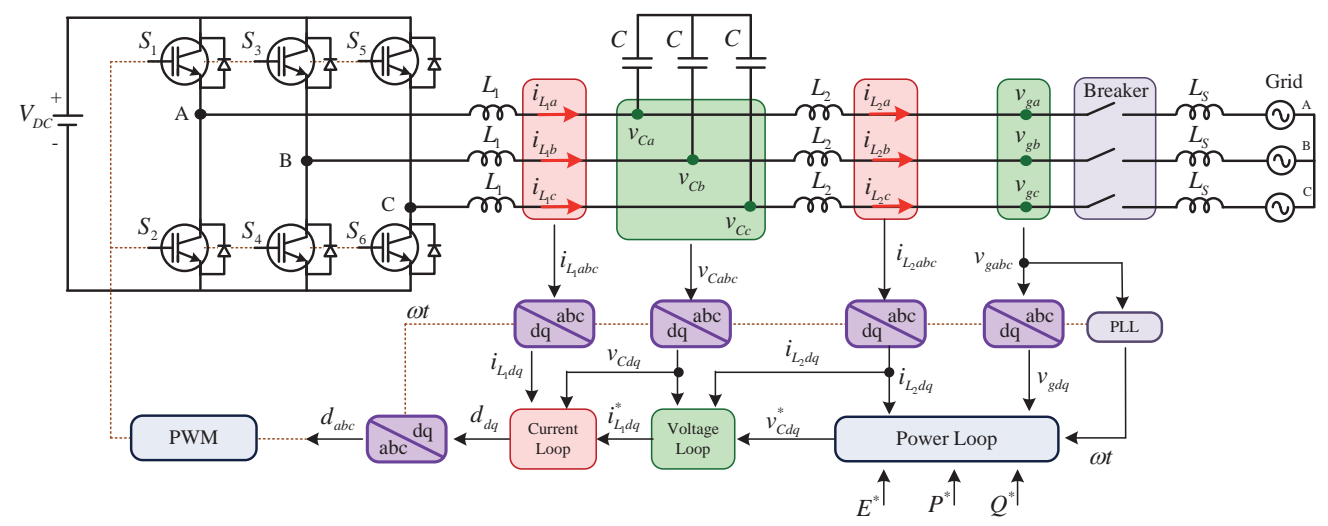

Fig. 1. Grid-Tie Three-Phase Inverter with LCL filter.

$\left[\begin{array}{l}i_{L_{1} d}^{*} \\ i_{L_{1} q}^{*}\end{array}\right]=\left[\begin{array}{c}z_{V d} \\ z_{V q}\end{array}\right]+\left[\begin{array}{l}i_{L_{2} d} \\ i_{L_{2} q}\end{array}\right]+\frac{3}{2} \omega C\left[\begin{array}{c}-V_{C q} \\ V_{C d}\end{array}\right]$.

Where:

$$
\left[\begin{array}{c}
z_{V d} \\
z_{V q}
\end{array}\right]=-C\left[\begin{array}{c}
\dot{e}_{V d} \\
\dot{e}_{V q}
\end{array}\right]
$$

\section{Power Loop Control}

The power loop control uses the well-know expressions for active and reactive power transfer [27]-[30], where active power is related to the power transfer angle and reactive power is related to the magnitude of the voltage. Concerning that the power transfer angle is small, the active and reactive power exhibited in (1) and (2) can be simplified as:

$$
\begin{gathered}
P=\frac{V_{C_{R U S}} V_{g_{\text {RUS }}}}{X_{L_{2}}} \delta \\
Q=\frac{V_{C_{\text {RUS }}} \cdot V_{g_{\text {RUS }}}}{X_{L_{2}}}-\frac{V_{g_{\text {RUS }}}{ }^{2}}{X_{L_{2}}}
\end{gathered}
$$

Therefore, the voltage reference for the voltage loop control can be generated by means of power loop as:

$$
\begin{aligned}
V_{C d}^{*} & =V_{C_{\text {RUS }}} \cos (\delta), \\
V_{C q}^{*} & =V_{C_{\text {RUS }}} \sin (\delta) .
\end{aligned}
$$

The error in the active power loop can be expressed as:

$$
e_{P}=P^{*}-P \text {. }
$$

The power transfer angle (21) can be obtained by means of the linearization process, which was applied in the derivative of the active power error (20), using the active power calculus (16) in its process.

$$
\delta=\frac{1}{V_{C_{d}}} \int z_{P} d t
$$

Where:

$$
\dot{e}_{P}=-\frac{z_{P} V_{g_{\text {RUS }}}}{X_{L_{2}}} .
$$

The error in the reactive power loop can be described as:

$$
e_{Q}=Q^{*}-Q
$$

Thus, the voltage reference (24) can be determined by means of the linearization method (7), which was applied in the derivative of the reactive power error (23), using (17) to obtain the reactive power value.

$$
V_{C_{R M S}}=\int z_{Q} d t
$$

Where:

$$
\dot{e}_{Q}=-\frac{z_{Q} V_{g_{R U S}}}{X_{L_{2}}} .
$$

In order to improve the dynamics in the power loop control the RMS voltage value across the capacitor $C\left(V_{C_{R M S}}\right)$ presented in (18), (19) and (21) is calculated as:

$$
V_{C_{R M S}}=\left(E^{*}+\Delta V_{C}\right) \text {. }
$$

Where $E^{*}$ is the RMS value of the grid voltage (phaseneutral), in this case $127 \mathrm{~V}, \Delta V_{C}$ is the deviation voltage necessary to compensate the reactive power into the grid, thus, this equation (24) was modified to improve the output voltage calculus (27). It was considered that the system operates only grid-connected. So for improving the dynamic responses of the power loop system the $V_{g_{R M S}}$ can be regarded as a constant value (e.g., $127 \mathrm{~V}$ ).

$$
\Delta V_{C}=\int z_{Q} d t
$$

The Matlab/Simulink ${ }^{\circledR}$ implementation for the proposed power loop used for voltage reference generation is depicted at Figure 2.

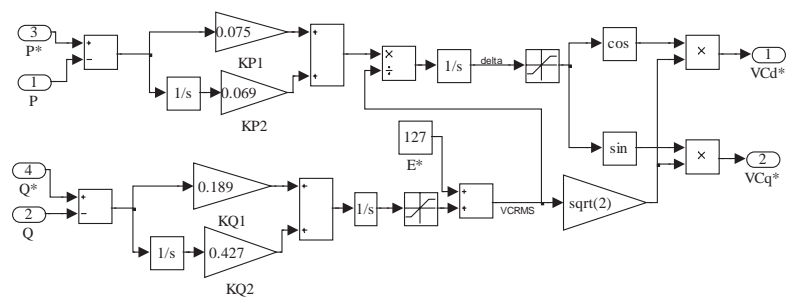

Fig. 2. Power Loop implementation in Matlab/Simulink®.

\section{E. LMI and D-Stability}

The equations that govern the state space modeling are described as:

$$
\begin{aligned}
& \dot{x}=A x+B u, \\
& y=C x .
\end{aligned}
$$

Concerning closed-loop linear systems and invariant-time domain, the main system is described as:

$$
\dot{x}=(A-B K) x .
$$

The linear matrix inequalities engaged in the solution of convex optimization problems is gaining even more attention 
due to several applications and great scope in the LMI usage. One of these applications is the pole placement (well-known as D-Stability) for closed-loop systems into the specified region of the complex plane, as shown in Figure 3. Table I illustrates the designated parameters for region $\mathrm{S}(\gamma, \sigma, \tau, \theta)$, to place the poles in the closed-loop systems.

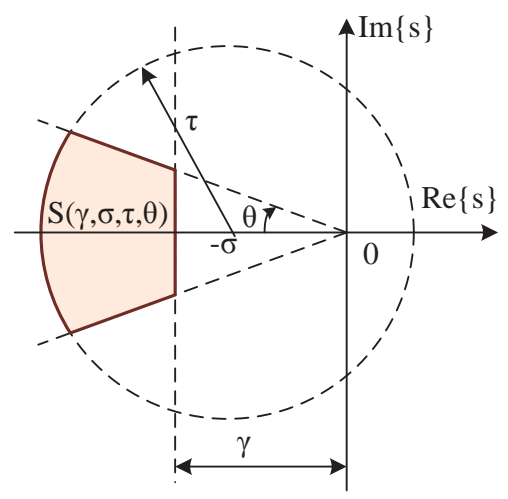

Fig. 3. Region $\mathbf{S}(\gamma, \sigma, \tau, \theta)$ for pole placement in closed-loop.

TABLE I

Parameters description for region $\mathrm{S}(\gamma, \sigma, \tau, \theta)$

\begin{tabular}{ll}
\hline Parameters & Description \\
\hline$\theta$ & $\begin{array}{l}\text { Boundary for imaginary poles part. It is related with } \\
\text { overshoot and transient response system. }\end{array}$ \\
\hline$\gamma$ & $\begin{array}{l}\text { Lower bound for placed poles module. It defines the } \\
\text { settling time. }\end{array}$ \\
\hline$\sigma, \tau$ & $\begin{array}{l}\text { Establish the upper bound for poles module. It defines the } \\
\text { controllers gain. }\end{array}$ \\
\hline
\end{tabular}

Generally, D-stability has the purpose to find the statefeedback controllers $K$ placing the poles (27) in a previously specified $\mathrm{S}(\gamma, \sigma, \tau, \theta)$ region in the left-half s-plane [23]-[26]. The main LMIs to solve the problem are defined as [19]-[20], [23]:

$$
\begin{gathered}
U>0, \\
A U+U A^{T}-B Y-Y^{T} B^{T}+2 \gamma U<0, \\
{\left[\begin{array}{cc}
-\tau U & A U-B Y+\sigma U \\
U A^{T}-Y^{T} B^{T}+\sigma U & -\tau U
\end{array}\right]<0,} \\
{\left[\begin{array}{cc}
\sin (\theta) \cdot\left(A U+U A^{T}-B Y-Y^{T} B^{T}\right) & \cos (\theta) \cdot\left(A U-U A^{T}-B Y+Y^{T} B^{T}\right) \\
\cos (\theta) \cdot\left(U A^{T}-A U+B Y-Y^{T} B^{T}\right) & \sin (\theta) \cdot\left(U A^{T}+A U-B Y-Y^{T} B^{T}\right)
\end{array}\right]<0 .}
\end{gathered}
$$

If (30) is feasible, then a state feedback $u=-K x$, is stabilized to place the poles in the closed-loop region $\mathrm{S}(\gamma, \sigma$, $\tau, \theta)$ if and only if there is a symmetric matrix $U$ and a matrix $Y$ such that a controller for such state feedback is given by $K=Y U^{-1}$.

\section{F. Controller Design}

The dynamic errors presented in (12), (15), (22) and (25) were linearized and linear controllers can be designed in this regions. Thus, several solutions are possible to be implemented. At this point one is implemented as example:

$$
z_{\beta}=\sum_{\alpha=1}^{\infty} K_{\beta \alpha} e_{\beta} .
$$

Where $\beta$ represents the signal from the current, voltage and power loop, and $\alpha$ represent the gain index $(1,2,3, \ldots)$.
By means of experimental tests, it was verified that the Proportional-Integral (PI) controller is an efficient solution to track the desired reference [12], [13]. Therefore, the linear system $z_{\beta}$ can be represented as:

$$
z_{\beta}=K_{\beta 1} e_{\beta}+K_{\beta 2} \int e_{\beta} d t
$$

The proportional and integral gains must be greater than zero, e.g., $K_{\beta 1}>0$ and $K_{\beta 2}>0$. It allows (32) to be expressed as:

$$
\dot{e}_{\beta}=-\frac{K_{\beta 1}}{G_{\beta}} e_{\beta}-\frac{K_{\beta 2}}{G_{\beta}} w_{\beta} .
$$

Where:

$$
w_{\beta}=\int e_{\beta} d t .
$$

The $G_{\beta}$ term represents the gain in the respective control loop, e.g., for the current control loop this term is equal to $L_{1}$.

The state-feedback matrix $\mathrm{K}$ can be obtained rewriting (33) and (34) into (29), as given as:

$$
\left[\begin{array}{c}
\dot{e}_{\beta} \\
\dot{w}_{\beta}
\end{array}\right]=\left(A_{\beta}-B_{\beta} K_{\beta}\right)\left[\begin{array}{c}
e_{\beta} \\
w_{\beta}
\end{array}\right] \text {. }
$$

Where:

$$
A_{\beta}=\left[\begin{array}{ll}
0 & 0 \\
1 & 0
\end{array}\right], B_{\beta}=\left[\begin{array}{c}
\frac{1}{G_{\beta}} \\
0
\end{array}\right], K_{\beta}=\left[\begin{array}{ll}
K_{\beta 1} & K_{\beta 2}
\end{array}\right] .
$$

Finally, the matrices (36) were introduced in (30), in order to obtain the state-feedback controllers.

\section{EXPERIMENTAL RESULTS}

The proposed control was implemented experimentally to demonstrate its feasibility for power flow control applied for the three-phase grid-tied inverter with LCL filter, using nonlinear and robust control. The main parameters used for the three-phase inverter are summarized in Table II.

\section{TABLE II}

Three-Phase Design Parameters

\begin{tabular}{ll}
\hline Parameters & Values \\
\hline DC Input Voltage (average) & $\mathrm{V}_{\mathrm{DC}}=500 \mathrm{~V}$ \\
\hline Grid Phase-neutral Voltage (rms) & $\mathrm{Vg}=127 \mathrm{~V}$ \\
\hline Nominal Output Power & $3000 \mathrm{VA}$ \\
\hline Switching frequency & $\mathrm{f}_{\mathrm{s}}=16 \mathrm{kHz}$ \\
\hline Inductor $L_{1}$ & $\mathrm{~L}_{1}=0.5 \mathrm{mH}$ \\
\hline Inductor $L_{2}$ & $\mathrm{~L}_{2}=7 \mathrm{mH}$ \\
\hline Capacitor $C$ & $\mathrm{C}=10 \mu \mathrm{F}$ \\
\hline
\end{tabular}

The control laws were implemented by means of the DSPACE ACE1104 digital platform. The grid emulator was performed using California MX45-3Pi and the DC voltage was supplied by Tectrol along with a Boost converter. Figure 4 shows the experimental set used to demonstrate the proposed control.

Despite the control systems were designed in continuous plane, the controllers were discretized by means of Tustin method, considering an acquisition frequency of $10 \mathrm{kHz}$. 
The controller gains were determined in Matlab® ${ }^{\circledR}$ with YALMIP [31] solver. The parameter $\gamma$ is well-known in the literature as decay rate [26]. This parameter is inserted into LMIs restriction to ensure the maximum time establishment for the norm of the vector states and it is given by (37). Where $x$ is the state vector; thus, the time establishment can be defined by (38). The parameters used to determine the $S(\gamma$, $\sigma, \tau, \theta)$ region in the left-half-s-plane and the controller gains obtained for the PI compensator are illustrated in Table III.

$$
\begin{gathered}
\lim _{t_{e} \rightarrow \infty} e^{-\gamma t_{e}}\|x\|=0 \\
t_{e}=\frac{6}{\gamma}
\end{gathered}
$$

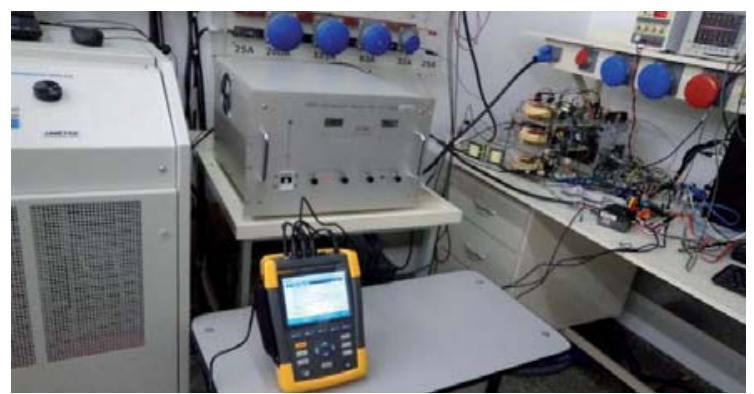

Fig. 4. Experimental set-up to demonstrate the feasibility of the proposed control.

TABLE III

Three-Phase PI Controller Parameters

\begin{tabular}{lcccccccc}
\hline \multirow{2}{*}{ Loop } & \multicolumn{4}{c}{ Parameters for } & \multicolumn{5}{c}{ PI - Controller } \\
\cline { 2 - 10 } & $\gamma$ & $\sigma$ & $\tau$ & $\theta$ & Kpd & Kid & Kpq & Kiq \\
\hline Active Power & 1.8 & 0 & 1.83 & $2^{\mathbf{o}}$ & 0.075 & 0.069 & - & - \\
\hline Reactive Power & 4.5 & 0 & 4.568 & $0.02^{\circ}$ & 0.189 & 0.427 & - & - \\
\hline Voltage & 1200 & 0 & 1201 & $1^{\circ}$ & 0.036 & 21.6 & 0.036 & 21.6 \\
\hline Current & 1200 & 0 & 1320 & $2^{\circ}$ & 1.260 & 792.98 & 1.260 & 792.98 \\
\hline
\end{tabular}

Figure 5 shows the Graphic User Interface (GUI). It is a friendly-user that allows easy management and control of the active power injection and reactive power compensation. The GUI was developed using the Control Desk (Dspace ${ }^{\circledR}$ Software Kit) environment. In its interface the power flow are able to be controlled and the main voltages and currents can be monitored in real time.

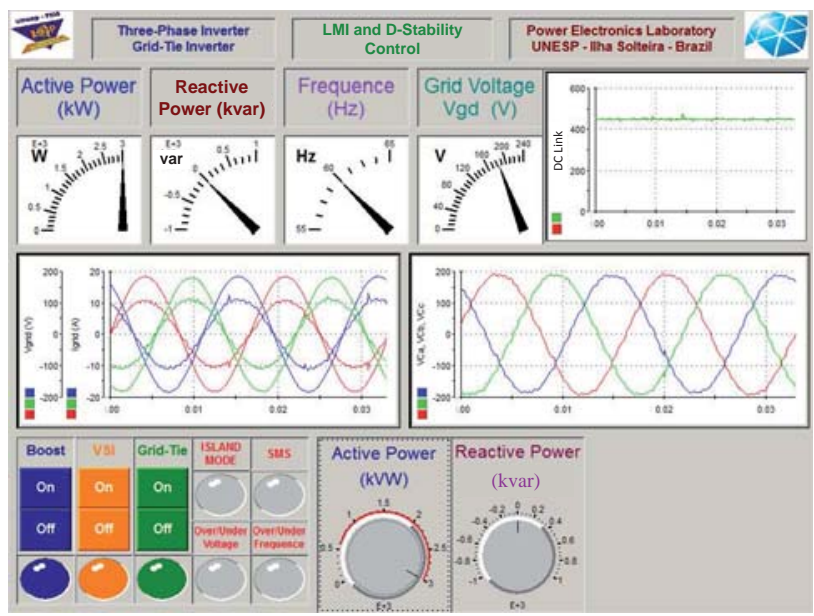

Fig. 5. GUI for Active and Reactive Power Flow Control.

\section{A. Results for normal grid operation}

Figures 6 and 7 show the active and reactive power flow tracking, where the power flow was transferred in fast way and one can observe that the proposed control allows fast response dynamics and the error in steady state is near to zero.

Some step power changes in the power references can be verified at Figures 6 and 7. The settling time for the power loop took about 1 second to set the new values of power transfer. As it can be noted the D-stability region should be adjusted so that the system operates within acceptable patterns from the grid.

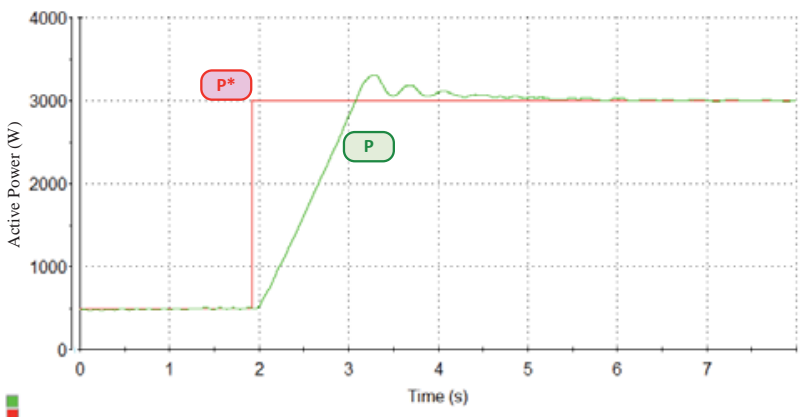

Fig. 6. Active Power tracking.

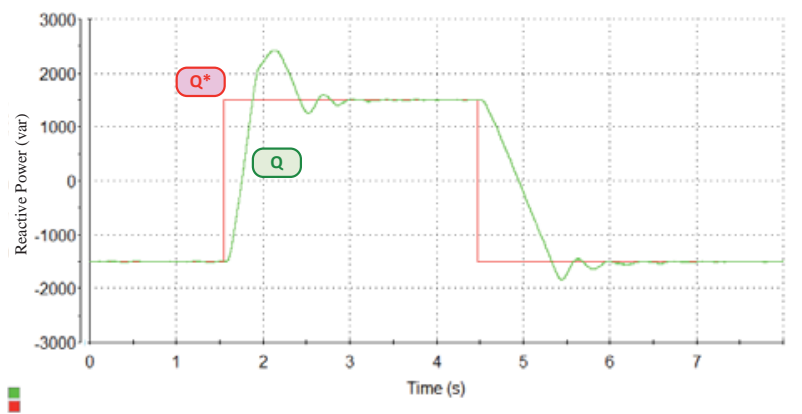

=

Fig. 7. Reactive Power tracking.

Considering a scenario that the DG must inject active and reactive power in a fast way, to guarantee the power quality, the proposed control allows a good relationship between speed and overshoot.

Figure 8 shows the grid voltage and the injection of current into the grid for nominal power $(3000 \mathrm{~W})(1 \mathrm{~kW}$ per phase). It can be observed that the THD is much lower than $5 \%$, the maximum value allowed by IEC standard [32].

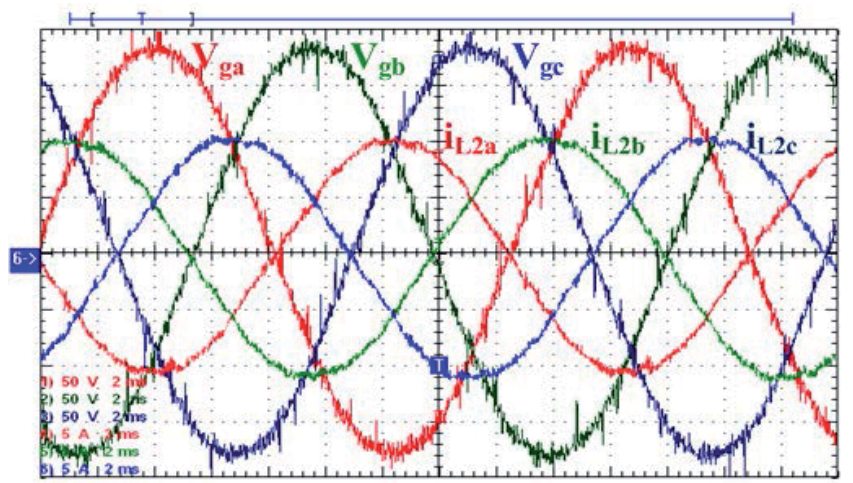

Fig. 8. Grid Voltage and Current Injection into the Grid for Nominal Power. Vg: 50 V/div; Ig: 5 A/div; Time: 2 ms/div. $T H D i_{L_{2} a}: 2.1 \% ; T H D i_{L_{L^{b}}}: 2.1 \% ; T H D i_{L_{2} c}: 2.3 \%$. 


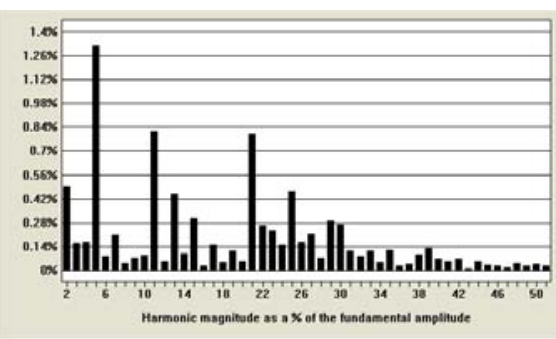

(a) Phase A

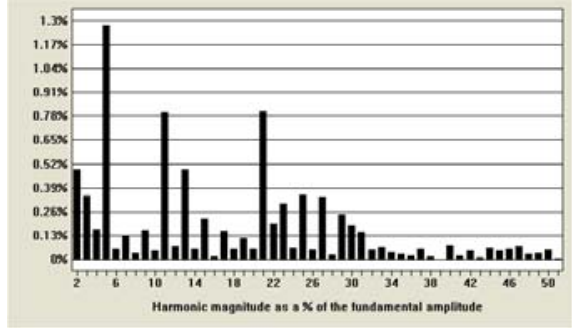

(b) Phase B

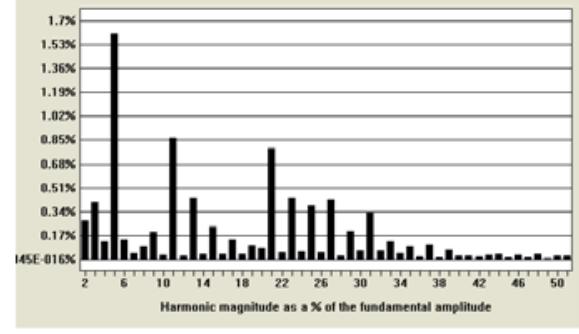

(c) Phase C

Fig. 9. Harmonic Distortion on the Injected Grid Current for Nominal Power $(P=3000 \mathrm{~W}$ e $\mathrm{Q}=0$ var).

The harmonic distortion of the injected grid current, considering the scenario of Figure 8, is presented at Figure 9. As it can be seen all three-phase harmonic contents are in compliance with IEC standard [32].

Figure 10 shows the grid voltage and current injection into the grid for active power injection of $2500 \mathrm{~W}$ and reactive power compensation of +1500 var. Figure 11 shows the grid voltage and current injection into the grid for active power injection of $2500 \mathrm{~W}$ and reactive power compensation of -1500 var. The apparent power was about $2.9 \mathrm{kVA}$ for both situations.

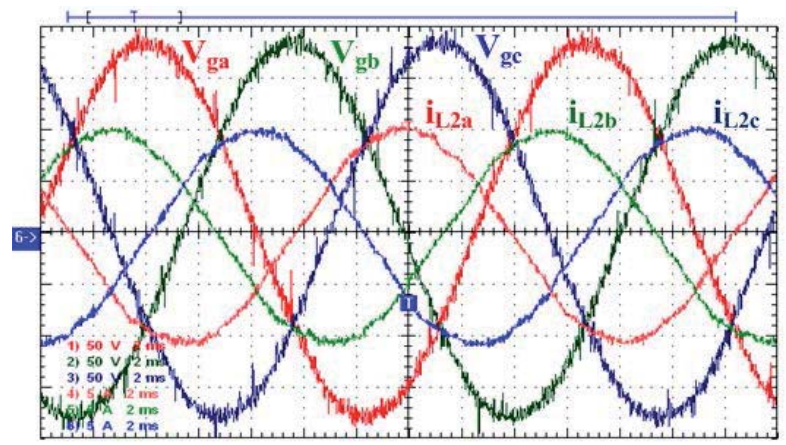

Fig. 10. Grid Voltage and Current Injection into the Grid for Active Power Injection of $2500 \mathrm{~W}$ and Reactive Power Compensation of 1500 var. Vg: $50 \mathrm{~V} /$ div; Ig: 5 A/div; Time: 2 ms/div.

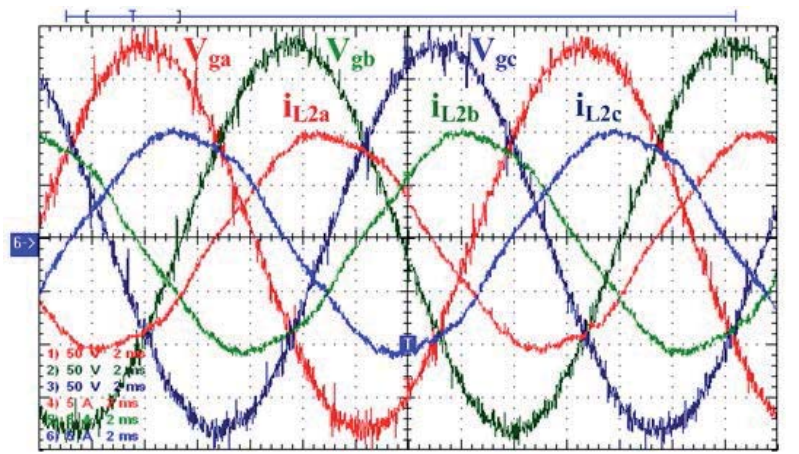

Fig. 11. Grid Voltage and Current Injection into the Grid for Active Power Injection of $2500 \mathrm{~W}$ and Reactive Power Compensation of 1500 var. Vg: $50 \mathrm{~V} /$ div; Ig: $5 \mathrm{~A} /$ div; Time: 2 ms/div.

\section{B. Results for Anti-Islanding and Protections}

Attending the standards requirements during the islanding mode and grid anomalous operation, it was used the SMS (Slide Mode Frequency Shift) [33] algorithm as active method and the over/under voltage and frequency were implemented through passive methods. Figure 12 shows the diagram block of the SMS algorithm.

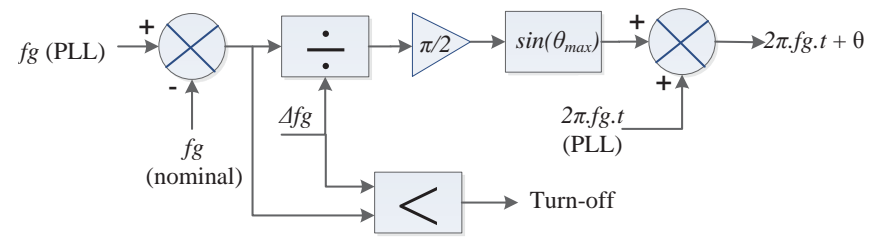

Fig. 12. SMS Algorithm Block Diagram.

The active power loop modify the power transfer angle in order to track the desired power, thus, naturally the control tries to modify the voltage frequency. As a result, the SMS algorithm was implemented together with the active power loop, with over/under voltage detection. Figure 13 shows the anti-islanding protection.

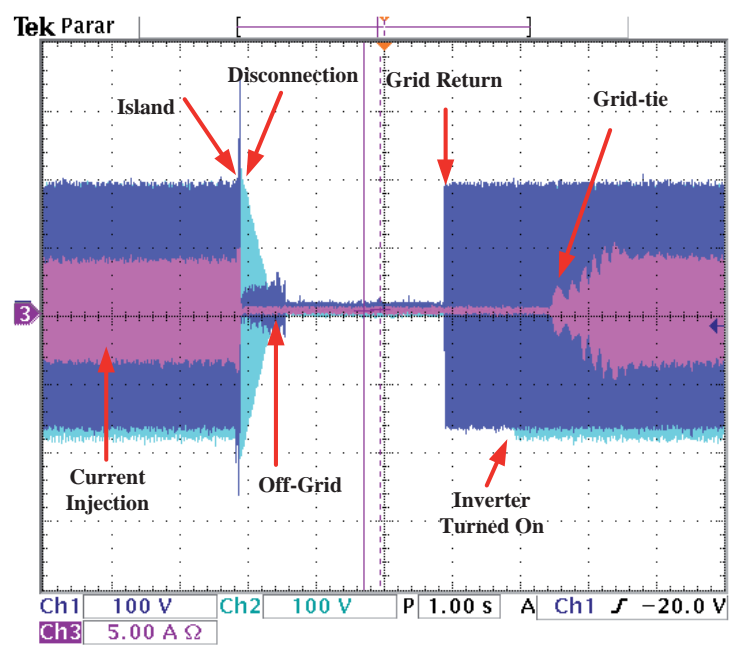

Fig. 13. Islanding Protection and Reconnection with the Grid.

The overvoltage and undervoltage protections were implemented using the direct-quadrature grid voltage, in accordance with the voltage limits given by IEC 62116 [32]. Figures 14 and 15 show the over and under voltage protections, respectively.

The protections against overfrequency and underfrequency were implemented by means of the verification of the grid voltage frequency, using the PLL frequency, as shown in Figures 16 and 17. It can be observed that the proposed protections can detect the frequency faults occurrence quickly below the time value defined by the IEC standard [32]. 


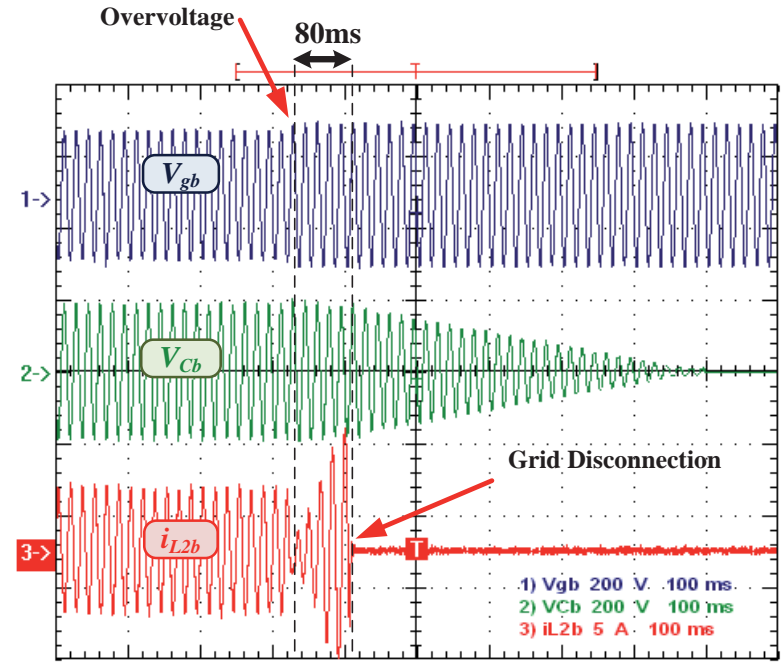

Fig. 14. Overvoltage Protection.

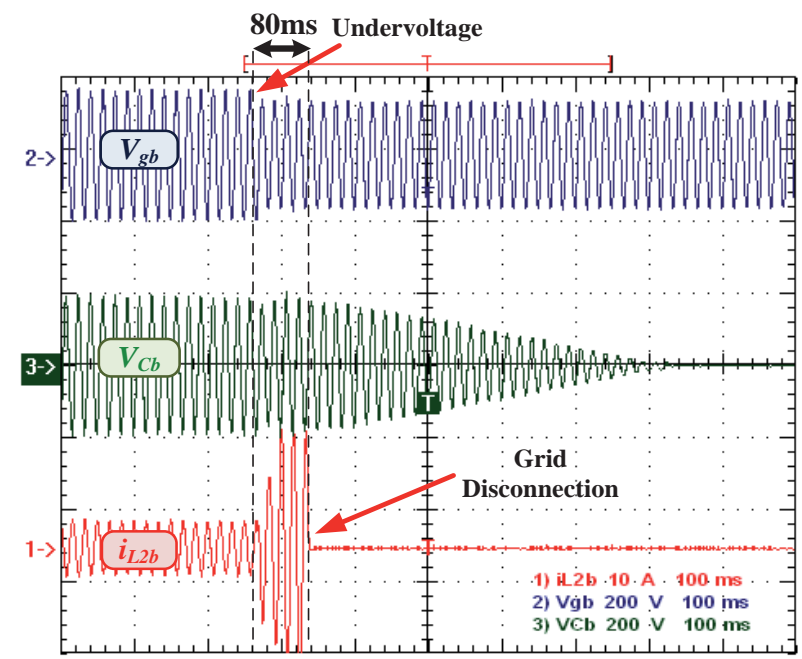

Fig. 15. Undervoltage Protection.

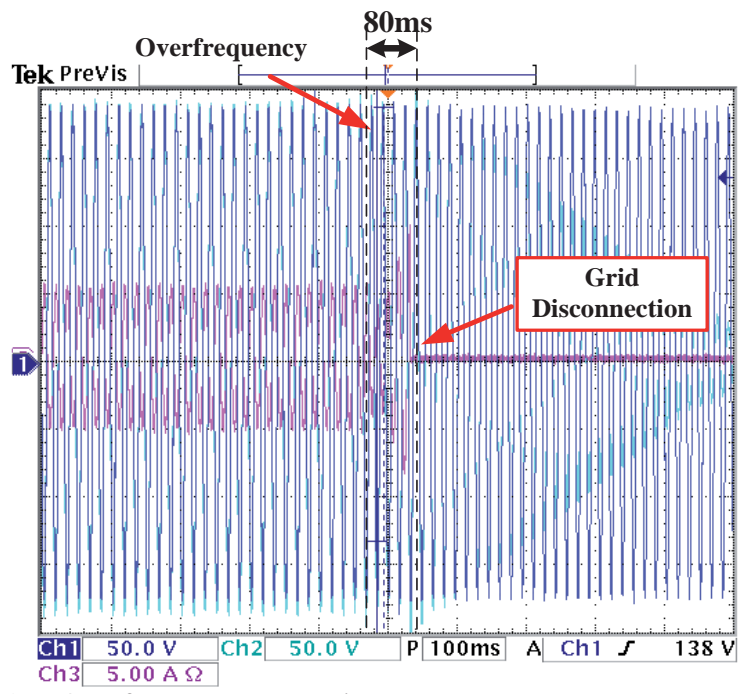

Fig. 16. Overfrequency Protection.

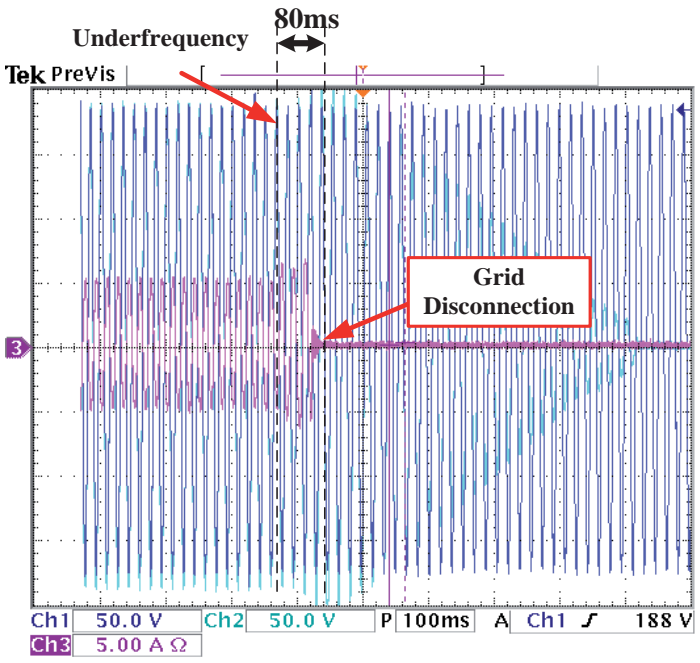

Fig. 17. Underfrequency Protection.

\section{CONCLUSION}

This paper presented a technique to control the active and reactive power flow between a DG and utility grid through a three-phase grid-tie inverter. The proposed technique uses state-feedback controller $\mathrm{K}$ with reduced gains and fast responses in order to track the desirables $\mathrm{P}^{*}$ and $\mathrm{Q}^{*}$ values, considering a micro-grid scenario with DG.

The experimental results demonstrated the feasibility of the proposed control, which can allows that the three-phase inverter operates with fast dynamics, providing current injection into the AC grid with low THD for any relationship between $\mathrm{P}^{*}$ and $\mathrm{Q}^{*}$. Furthermore, the paper presented experimental results for anti-islanding detection and protections against over/undervoltage and over/underfrequency. These algorithms are extremely important to comply with standards, to protect and prevent accidents over connections between the DG and the utility grid, and finally, for the power utility consumers.

The proposed control used a nonlinear control technique named as feedback linearization to attenuate possible disturbances and nonlinearities presents in the system. Furthermore, the controllers were designed by means of the Linear Matrix inequalities with D-stability criteria, in order to ensure the pole placement in a specified region of the splane.

\section{ACKNOWLEDGEMENT}

The authors would like to thank FAPESP, CNPq, CAPES and Semikron for financial support given to the development of this work.

\section{REFERENCES}

[1] M. A. G. de Brito, L. P. Sampaio, L. Galotto Jr., C. A. Canesin, "Evaluation of the Main MPPT Techniques for Photovoltaic Applications", IEEE Transactions on Industrial Electronics, vol. 60, no. 3, pp. 1156-1167, March 2013.

[2] A. Consoli, M. Cacciato, V. Crisafulli, "Power Converters for Photovoltaic Generation Systems in 
Smart Grid Applications", Eletrônica de Potência, vol. 14, no. 4, pp. 251-257, December 2009.

[3] R. F. Arritt, R. C. Dugan, "Distribution System Analysis and the Future Smart Grid", IEEE Transactions on Industry Applications, vol. 47, no. 6, pp. 2343-2350, November/December 2011.

[4] R. H. Lasseter, "Smart Distribution: Coupled Microgrids", in Proc. of IEEE, vol. 99, no. 6, pp. 10741082, 2011.

[5] REN21 - "Renewables 2011: Global status report", [s.1.;s.n], Avaliable from: <http://www.ren21.net>, accessed May 2012.

[6] M. A. G. de Brito, L. P. Sampaio, M. G. Alves, C. A. Canesin, "Inversor Buck-boost Tri-state Integrado Trifásico Para Aplicações Fotovoltáicas”, Eletrônica de Potência, vol. 19, no. 1, pp. 81-89, February 2014.

[7] P. M. de Almeida, P. G. Barbosa, A. A. Ferreira, H. A. C. Braga, P. F. Ribeiro, "Controle E Redução Das Correntes Harmônicas De Um Sistema De Geração Fotovoltaico Interligado à Rede Elétrica Sem Filtros Passivos", Eletrônica de Potência, vol. 18, no. 4, pp. 1149 - 1160, November 2013.

[8] P. Sun, C. Liu, J.-S. Lai,C.-L. Chen, "Grid-Tie Control of Cascade Dual-Buck Inverter with Wide-Range Power Flow Capability for Renewable Energy Applications", IEEE Transactions on Power Electronics, vol. 27, no. 4, pp. 1839-1849, April 2012.

[9] Y. Zhou, W. Huang, P. Zhao, J. Zhao, “A Transformerless Grid-Connected Photovoltaic System Based on the Coupled Inductor Single-Stage Boost Three-Phase Inverter", IEEE Transactions on Power Electronics, vol. 29, no. 3, pp. 1041-1046, March 2014.

[10]D. C. Martins, M. F. Schonardie, R. F. Coelho, L. Schmitz, "Active And Reactive Power Control In A Three-phase Grid-connected Pv Power System Using Dq0 Transformation", Eletrônica de Potência, vol. 18, no. 4, pp. 1180-1187, November 2014.

[11]B. Bahrani, A. Karimi, B. Rey, A. Rufer, "Decoupled dq-Current Control of Grid-Tied Voltage Source Converters Using Nonparametric Models", IEEE Transactions on Industrial Electronics, vol. 60, no. 4, pp.1356-1366, April 2013.

[12]R. W. Erickson, D. Maksimović, Fundamentals of Power Electronics, Kluwer Academic Publisher, 2nd Edition, USA, 2001.

[13] L. P. Sampaio, M. A. G. de Brito, L. Galotto Junior, G. de A. Melo, C. A. Canesin, "Single-phase currentsource-boost inverter for renewable energy sources", in Proc. of ISIE, vol. 20, pp.1118-1123, 2011.

[14]A. Isidori, Nonlinear Control Systems, Springer Verlag, $3^{\text {rd }}$ Edition, London, United Kingdom, 1995.

[15] G. Chu, C. K. Tse, Siu Chung Wong, Siew-Chong Tan, "A Unified Approach for the Derivation of Robust Control for Boost PFC Converters", IEEE Transactions on Power Electronics, vol. 24, no.11, pp. 2531-2544, November 2009.

[16] G. Uicich, S. Maestri, M. Benedetti, D. Carrica, “A Nonlinear Approach for Assessing Stability in LineCommutated Converters with an Integrating Controller", IEEE Transactions on Power Electronics, vol. 29, no. 1, pp. 339-346, January 2014
[17] J. Mash, M. Pahlevaninezhad, P. Jain, “Adaptive passivity-based nonlinear controller for wind energy conversion systems", in Proc. of APEC, pp. 1757-1764, 2014.

[18] S. Boyd, L. El Ghaoui, E. Feron, V. Balakrishnan, Linear matrix inequalities in system and control theory, Society for Industrial and Applied Mathematics, [s. 1.], vol. 15, 1994.

[19] L. P. Sampaio, M. A. G. de Brito, G. A e Melo, C. A. Canesin, "Inversor Monofásico para Geração Distribuída Conectada à Rede Elétrica, com Injeção de Potência Ativa e Capacidade de Compensação Reativa", Eletrônica de Potência, vol. 19, no. 1, pp. 90-97, February 2014.

[20] L. P. Sampaio, M. A. G. de Brito, M. G. Alves, G. A e Melo, C. A. Canesin, "Grid-tie Three-phase Inverter With Active And Reactive Power Flow Control Capability", in Proc. of COBEP, vol. 12, pp. 1039-1045, 2013.

[21] A. Kahrobaeian, Y. A. Mohamed, "Robust Single-Loop Direct Current Control of LCL-Filtered Converter-Based DG Units in Grid-Connected and Autonomous Microgrid Modes", IEEE Transactions on Power Electronics, vol. 29, no. 10, pp. 5605-5619, October 2014.

[22] M. Dahmane, J. Bosche, A. El-Hajjaji, "Robust control approach for photovoltaic conversion system", in Proc. of IRSEC, pp. 123-129, 2013.

[23] C. Olalla, I. Queinnec, R. Leyva, A. El-Aroudi, "Optimal State-Feedback Control of Bilinear DC-DC Converters With Guaranteed Regions of Stability", IEEE Transactions on Industrial Electronics, vol. 59, no. 10, pp. 3868-3880, October 2012.

[24]A. Benzaouia, H. M. Soliman, M. Chaabane, "Stabilization by pole placement of constrained uncertain systems: Application to a buck converter", in Proc. of STA, pp. 448-452, 2013.

[25]E. Assunção, C. Q. Andrea, M. C. M. Teixeira, "Alocação de zeros aplicada a sistemas de controle via LMI”, Controle \& Automação, vol. 18, no. 1, pp. 55-66, March 2007.

[26] M. Chilali, P. Gahinet, "Hळ design with pole placement constraints: an LMI approach", IEEE Transactions on Automatic Control, vol. 41, no. 3, pp. 358-367, March 1996.

[27]M. J. Kurtz, M. A. Henson, "Input-Output linearizing control of constrained nonlinear processes", Journal of Process Control, vol. 7, no. 1, pp. 3-17, February 1997.

[28] R. B. Godoy, C. A. Canesin, J. O. P. Pinto, A. M. A. C. Pinto , E. A. A. Coelho, "Differential Evolution Based Optimization of the Dynamic Response for Parallel Operation of Inverters with no Controllers Interconnection", IEEE Transactions on Industrial Electronics, vol. 59, no. 7, pp. 2859-2866, July 2012.

[29]R. B. Godoy, L. A. Carniato; J. O. P. Pinto, C. A. Canesin, R. Cordero, "Power flow optimization for grid connected inverter using evolutionary algorithm and additional control loop", in Proc. of COBEP, vol. 11, pp. 422-427, 2011.

[30] R. B. Godoy, J. O. P. Pinto, C. A. Canesin . “Optimized Paralelism of Two Single Phase Inverters Based on Evolutionary Theory", in Proc. of SPEEDAM, pp. 11351140, 2010. 
[31]J. Lofberg, "YALMIP: a toolbox for modeling and optimization in MATLAB", in Proc. of CACSD, vol. 13, pp. 284-289, 2004.

[32] IEC Standard 62116:2008, “Test procedure of islanding prevention measures for utility-interconnected photovoltaic inverters", IEC standard, $1^{\text {st }}$ Edition, [s.1.], 2008.

[33] P. Mahat, Z. Chen, B. Bak-Jensen, T. Matsuoka, "Review of Islanding Detection Methods for Distributed Generation", in Proc. of DRPT, vol. 3, pp. 2743-2748, 2008.

\section{BIOGRAPHIES}

Leonardo Poltronieri Sampaio, was born in São José do Rio Preto, SP, Brazil, in 1983. He received the B.Sc., M.Sc. and Ph.D. degrees all in electrical engineering from São Paulo State University (UNESP), Ilha Solteira-SP, Brazil, in 2008, 2010 and 2013, respectively. Since 2012, he has been Professor at Technological University of Paraná (UTFPR) - Cornélio Procópio Brazil. His interests include computer programming, education in power electronics, education tools, DC-DC converters, inverters, renewable and alternative energy source, photovoltaic systems, power electronic converters.

Moacyr Aureliano Gomes de Brito, was born in Andradina, Brazil, in 1982. He received the B.S., M.Sc. and Ph.D degrees all in electrical engineering from São Paulo State University (UNESP), Ilha Solteira-SP, Brazil, in 2005, 2008 and 2013, respectively. Nowadays, he is Adjunct Professor at Technological University of Paraná (UTFPR) - Campo Mourão - Brazil. His interests include ballasts for fluorescent lamps, dimming control, digital control, dcto-dc converters, switching-mode power supplies, power-factorcorrection techniques, field-programmable gate arrays, and standalone and grid-connected inverters for photovoltaic applications.
Guilherme de Azevedo e Melo, received the B.S., M.S. and $\mathrm{Ph} . \mathrm{D}$. degrees all in electrical engineering from São Paulo State University (UNESP), Ilha Solteira, Brazil, in 2001, 2006, and 2010, respectively. Since 2010, he has been a Collaborator Professor with FEIS, UNESP, where he is currently a Member of the Power Electronics Laboratory (LEP). Dr. Melo principal interest areas are power electronics, electrical power quality and renewable energies.

Carlos Alberto Canesin, received the B.S. degree from São Paulo State University-UNESP, Ilha Solteira (SP), Brazil, in 1984 and the M.S. and Ph.D. degrees from the Federal University of Santa Catarina, Florianópolis (SC), Brazil, in 1990 and 1996, respectively, all in electrical engineering. Currently, Dr. Canesin is a Full Professor at São Paulo State University-UNESP. He started the Power Electronics Laboratory- LEP in 1991, at the UNESP São Paulo State University, Ilha Solteira (SP), Brazil (http://www.lep.dee.feis.unesp.br/). Dr. Canesin is an Associate Editor for the IEEE Transactions on Power Electronics, IEEE Institute of Electrical and Electronics Engineers, since 2003, and currently (since 2010) he is a member of The State of São Paulo Council for Energetic Political (CEPE). From Jan/2003 to Dec/2004 he was Editor of the The Brazilian Journal of Power Electronics, edited by SOBRAEP - Brazilian Power Electronics Society, where he is currently a member of Editorial Council. From Nov/2004 to Oct/2006, he was the President of SOBRAEP, the Brazilian Power Electronics Society, where he is currently a permanent member of Deliberative Council. His interests include power quality analysis and techniques, active power-factor correction techniques, highpower factor rectifiers, soft-switching techniques, dc-to-dc converters, dc-to-ac converters, switching-mode power supplies, solar/photovoltaic energy and eolic/wind energy applications, pure electrical vehicles, electronic fluorescent ballasts, and educational research in power electronics. 